\title{
Obstetric anal sphincter injury: Prevention and repair
}

\author{
The repair of anal sphincter injury continues to evolve. Consider \\ incorporating the ideas in this editorial in your practice.
}

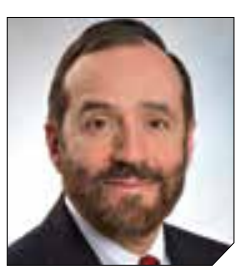

Robert L. Barbieri, MD

Chair Emeritus, Department of Obstetrics and Gynecology

Interim Chief, Obstetrics

Brigham and Women's Hospital

Kate Macy Ladd Distinguished Professor of Obstetrics,

Gynecology and Reproductive Biology

Harvard Medical School

Boston, Massachusetts
T

he rate of obstetric anal sphincter injury (OASIS) is approximately $4.4 \%$ of vaginal deliveries, with $3.3 \%$ 3rd-degree tears and $1.1 \%$ 4th-degree tears. ${ }^{1}$ In the United States in 2019 there were $3,745,540$ births-a $31.7 \%$ rate of cesarean delivery (CD) and a $68.3 \%$ rate of vaginal delivery-resulting in approximately 112,600 births with OASIS. ${ }^{2}$ A meta-analysis reported that, among 716,031 vaginal births, the risk factors for OASIS included: forceps delivery (relative risk [RR], 3.15), midline episiotomy (RR, 2.88), occiput posterior fetal position (RR, 2.73), vacuum delivery (RR, 2.60), Asian race (RR, 1.87), primiparity (RR, 1.59), mediolateral episiotomy (RR, 1.55), augmentation of labor (RR, 1.46), and epidural anesthesia (RR, 1.21). ${ }^{3}$ OASIS is associated with an increased risk for developing postpartum perineal pain, anal incontinence, dyspareunia, and wound breakdown. ${ }^{4}$ Complications following OASIS repair can trigger many followup appointments to assess wound healing and provide physical therapy.

This editorial review focuses on evolving recommendations for preventing and repairing OASIS.

doi: 10.12788/obgm.0099
The optimal cutting angle for a mediolateral episiotomy is 60 degrees from the midline

For spontaneous vaginal delivery, a policy of restricted episiotomy reduces the risk of OASIS by approximately $30 \% .{ }^{5}$ With an operative vaginal delivery, especially forceps delivery of a large fetus in the occiput posterior position, a mediolateral episiotomy may help to reduce the risk of OASIS, although there are minimal data from clinical trials to support this practice. In one clinical trial, 407 women were randomly assigned to either a mediolateral or midline episiotomy. ${ }^{6}$ Approximately $25 \%$ of the births in both groups were operative deliveries. The mediolateral episiotomy began in the posterior midline of the vaginal introitus and was carried to the right side of the anal sphincter for $3 \mathrm{~cm}$ to $4 \mathrm{~cm}$. The midline episiotomy began in the posterior midline of the vagina and was carried $2 \mathrm{~cm}$ to $3 \mathrm{~cm}$ into the midline perineal tissue. In the women having a midline or mediolateral episiotomy, a 4th-degree tear occurred in $5.5 \%$ and $0.4 \%$ of births, respectively. For the midline or mediolateral episiotomy, a third-degree tear occurred in $\mathbf{1 8 . 4 \%}$ and $8.6 \%$, respectively. In a prospective cohort study of 1,302 women with an episiotomy and vaginal birth, the rate of OASIS associated with midline or mediolateral episiotomy was $14.8 \%$ and $7 \%$, respectively $(P<.05) .^{7}$ In this study, the operative vaginal delivery rate was $11.6 \%$ and $15.2 \%$ for the women in the midline and mediolateral groups, respectively.

The angle of the mediolateral episiotomy may influence the rate of OASIS and persistent postpartum perineal pain. In one study, 330 nulliparous women who were assessed to need a mediolateral episiotomy at delivery were randomized to an incision with a 40 - or 60 -degree angle from the midline. ${ }^{8}$ Prior to incision, a line was drawn on the skin to mark the course of the incision and then infiltrated with $10 \mathrm{~mL}$ of lignocaine. The fetal head was delivered with a Ritgen maneuver. The length of the episiotomy averaged $4 \mathrm{~cm}$ in both groups. After delivery, the angle of the episiotomy incision was reassessed. The episiotomy incision cut 60 degrees from the midline was measured on average to be 44 degrees from the midline after delivery of the newborn. Similarly, the incision cut at a 40-degree angle was measured to be 24 degrees from the midline after delivery. The rates 
of OASIS in the women who had a 40- and 60-degree angle incision were $5.5 \%$ and $2.4 \%$, respectively $(P=.16)$.

\section{Use a prophylactic antibiotic with extended coverage for anaerobes prior to or during your anal sphincter repair}

Many experts recommend one dose of a prophylactic antibiotic prior to, or during, OASIS repair in order to reduce the risk of wound complications. In a trial 147 women with OASIS were randomly assigned to receive one dose of a second-generation cephalosporin (cefotetan or cefoxitin) with extended anaerobic coverage or a placebo just before repair of the laceration. ${ }^{9}$ At 2 weeks postpartum, perineal wound complications were significantly lower in women receiving one dose of prophylactic antibiotic with extended anaerobe coverage compared with placebo- $8.2 \%$ and $24.1 \%$, respectively $(P=.037)$. Additionally, at 2 weeks postpartum, purulent wound discharge was significantly lower in women receiving antibiotic versus placebo, $4 \%$ and

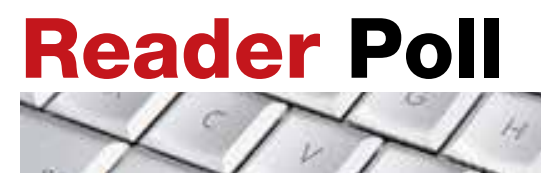

Do you use intrapartum warm compresses to the perineum or perineal massage in your practice?

Tell us at

rbarbieri@mdedge.com.

Please include your name and city and state.
$17 \%$, respectively $(P=.036)$. Experts writing for the Society of Obstetricians and Gynaecologists of Canada also recommend one dose of cefotetan or cefoxitin..$^{10}$ Extended anaerobic coverage also can be achieved by administering a single dose of BOTH cefazolin $2 \mathrm{~g}$ by intravenous (IV) infusion PLUS metronidazole $500 \mathrm{mg}$ by IV infusion or oral medication. ${ }^{11}$ For women with severe penicillin allergy, a recommended regimen is gentamicin $5 \mathrm{mg} / \mathrm{kg}$ plus clindamycin $900 \mathrm{mg}$ by IV infusion. ${ }^{11}$ There is evidence that for colorectal or hysterectomy surgery, expanding prophylactic antibiotic coverage of anaerobes with cefazolin PLUS metronidazole significantly reduces postoperative surgical site infection. ${ }^{12,13}$ Following an OASIS repair, wound breakdown is a catastrophic problem that may take many months to resolve. Administration of a prophylactic antibiotic with extended coverage of anaerobes may help to prevent wound breakdown.

\section{Prioritize identifying and separately repairing the internal anal sphincter}

The internal anal sphincter is a smooth muscle that runs along the outside of the rectal wall and thickens into a sphincter toward the anal canal. The internal anal sphincter is thin and greywhite in appearance, like a veil. By contrast, the external anal sphincter is a thick band of red striated muscle tissue. In one study of 3,333 primiparous women with OASIS, an internal anal sphincter injury was detected in $33 \%$ of cases. ${ }^{14}$ In this large cohort, the rate of internal anal sphincter injury with a 3A tear, a 3B tear, a complete tear of the external sphincter and a 4th-degree perineal tear was $22 \%, 23 \%, 42 \%$, and $71 \%$, respectively. The internal anal sphincter is important for maintaining rectal continence and is estimated to contribute $50 \%$ to $85 \%$ of resting anal tone..$^{15}$ If injury to the internal anal sphincter is detected at a birth with an OASIS, it is important to separately repair the internal anal sphincter to reduce the risk of postpartum rectal incontinence. ${ }^{16}$

\section{Polyglactin 910 vs Polydioxanone (PDS)} Suture-Is PDS the winner? Polyglactin 910 (Vicryl) is a braided suture that is absorbed within 56 to 70 days. Polydioxanone suture is a long-lasting monofilament suture that is absorbed within 200 days. Many colorectal surgeons and urogynecologists prefer PDS suture for the repair of both the internal and external anal sphincters. ${ }^{16}$ Authors of one randomized trial of OASIS repair with Vicryl or PDS suture did not report significant differences in most clinical outcomes. ${ }^{17}$ However, in this study, anal endosonographic imaging of the internal and external anal sphincter demonstrated more internal sphincter defects but not external sphincter defects when the repair was performed with Vicryl rather than PDS. The investigators concluded that comprehensive training of the surgeon, not choice of suture, is probably the most important factor in achieving a good OASIS repair. However, because many subspecialists favor PDS suture for sphincter repair, specialists in obstetrics and gynecology should consider this option.

\section{Can your patient access early secondary repair if they develop a perineal laceration wound breakdown?}

The breakdown of an OASIS repair is an obstetric catastrophe with complications that can last many months 


\section{Do you use intrapartum warm compresses to the perineum or perineal massage in your practice?}

A Cochrane Database Systematic Review reported that moderate-quality evidence showed a decrease in OASIS with the use of intrapartum warm compresses to the perineum and perineal massage. ${ }^{1}$ Compared with control, intrapartum warm compresses to the perineum did not result in a reduction in first- or second-degree tears, suturing of perineal tears, or use of episiotomy. However, compared with control, intrapartum warm compresses to the perineum was associated with a reduction in OASIS (relative risk [RR], 0.46; 95\% confidence interval [CI], 0.27-0.79; 1,799 women; 4 studies; moderate quality evidence; substantial heterogeneity among studies). In addition to a possible reduction in OASIS, warm compresses also may provide the laboring woman, especially those having a natural childbirth, a positive sensory experience and reinforce her perception of the thoughtfulness and caring of her clinicians.

Compared with control, perineal massage was associated with an increase in the rate of an intact perineum (RR, 1.74; 95\% CI, 1.11-2.73; 6 studies; 2,618 women; low-quality evidence; substantial heterogeneity among studies) and a decrease in OASIS (RR, 0.49; 95\% CI, 0.25-0.94; 5 studies; 2,477 women; moderate quality evidence). Compared with control, perineal massage did not significantly reduce first- or second-degree tears, perineal tears requiring suturing, or the use of episiotomy (very low-quality evidence). Although perineal massage may have benefit, excessive perineal massage likely can contribute to tissue edema and epithelial trauma.

Reference

1. Aasheim V, Nilsen ABC, Reinar LM, et al. Perineal techniques during the second stage of labour for reducing perineal trauma. Cochrane Database Syst Rev. 2017;CD006672.

and sometimes stretch into years. The best approach to a perineal laceration wound breakdown remains controversial. It is optimal if all patients with a wound breakdown can be offered an early secondary repair or healing by secondary intention, permitting the patient to select the best approach for their specific situation.

As noted by the pioneers of early repair of episiotomy dehiscence, Drs. Hankins, Haugh, Gilstrap, Ramin, and others, ${ }^{18-20}$ conventional doctrine is that an episiotomy repair dehiscence should be managed expectantly, allowing healing by secondary intention and delaying repair of the sphincters for a minimum of 3 to 4 months. $^{21}$ However, many small case-series report that early secondary repair of a perineal laceration wound breakdown is possible following multiple days of wound preparation prior to the repair, good surgical technique and diligent postoperative follow-up care. One large case series reported on 72 women with complete perineal wound dehiscence who had early secondary repair. ${ }^{22}$ The median time to complete wound healing following early repair was 28 days. About $36 \%$ of the patients had one or more complications, including skin dehiscence, granuloma formation, perineal pain, and sinus formation. A pilot randomized trial reported that, compared with expectant management of a wound breakdown, early repair resulted in a shorter time to wound healing. ${ }^{23}$

Early repair of perineal wound dehiscence often involves a course of care that extends over multiple weeks. As an example, following a vaginal birth with OASIS and immediate repair, the patient is often discharged from the hospital to home on postpartum day 3 . The wound breakdown often is detected between postpartum days 6 to 10 .
If early secondary repair is selected as the best treatment, 1 to 6 days of daily debridement of the wound is needed to prepare the wound for early secondary repair. The daily debridement required to prepare the wound for early repair is often performed in the hospital, potentially disrupting early mother-newborn bonding. Following the repair, the patient is observed in the hospital for 1 to 3 days and then discharged home with daily wound care and multiple follow-up visits to monitor wound healing. Pelvic floor physical therapy may be initiated when the wound is healed. The prolonged process required for early secondary repair may be best undertaken by a subspecialty practice. ${ }^{24}$

The surgical repair and postpartum care of OASIS continues to evolve. In your practice you should consider:

- performing a mediolateral episiotomy at a 60-degree angle to 
reduce the risk of OASIS in situations where there is a high risk of anal sphincter injury, such as in forceps delivery

- using one dose of a prophylactic antibiotic with extended anaerobic coverage, such as cefotetan or cefoxitin

- focus on identifying and separately repairing an internal anal sphincter injury

References

1. Friedman AM, Ananth CV, Prendergast E, et al. Evaluation of third-degree and fourth-degree laceration rates as quality indicators. Obstet Gynecol. 2015;125:927-937.

2. Hamilton BE, Martin JA, Osterman MK. Births: Provisional data for 2019. Vital Statistics Rapid Release; No. 8. Hyattsville MD: National Center for Health Statistics; May 2020. https://www.cdc. gov/nchs/data/vsrr/vsrr-8-508.pdf

3. Pergialitotis V, Bellos I, Fanaki M, et al. Risk factors for severe perineal trauma during childbirth: an updated meta-analysis. European J Obstet Gynecol Repro Biol. 2020;247:94-100.

4. Sultan AH, Kettle C. Diagnosis of perineal trauma. In: Sultan AH, Thakar R, Fenner DE, eds. Perineal and anal sphincter trauma. 1st ed. London, England: Springer-Verlag; 2009:33-51.

5. Jiang H, Qian X, Carroli G, et al. Selective versus routine use of episiotomy for vaginal birth. Cochrane Database Syst Rev. 2017;CD000081.

6. Coats PM, Chan KK, Wilkins M, et al. A comparison between midline and mediolateral episiotomies. Br J Obstet Gynaecol. 1980;87:408-412.

7. Sooklim R, Thinkhamrop J, Lumbiganon $\mathrm{P}$, et al. The outcomes of midline versus medio-lateral episiotomy. Reprod Health. 2007;4:10.

8. El-Din AS, Kamal MM, Amin MA. Comparison between two incision angles of mediolateral episiotomy in primiparous women: a randomized controlled trial. J Obstet Gynaecol Res. 2014;40:1877-1882.

9. Duggal N, Mercado C, Daniels K, et al. Antibiotic
- using a long-lasting absorbable suture, such as PDS, to repair the internal and external anal sphincters

- ensuring that the patient with a dehiscence following an episiotomy or anal sphincter injury has access to early secondary repair. Standardizing your approach to the prevention and repair of anal sphincter injury will benefit the

prophylaxis for prevention of postpartum perineal wound complications: a randomized controlled trial. Obstet Gynecol. 2008;111:1268-1273.

10. Harvey MA, Pierce M. Obstetrical anal sphincter injuries (OASIS): prevention, recognition and repair. J Obstet Gynecol Can. 2015;37:1131-1148.

11. Cox CK, Bugosh MD, Fenner DE, et al. Antibiotic use during repair of obstetrical anal sphincter injury: a qualitative improvement initiative. Int $J$ Gynaecol Obstet. 2021; Epub January 28.

12. Deierhoi RJ, Dawes LG, Vick C, et al. Choice of intravenous antibiotic prophylaxis for colorectal surgery does matter. J Am Coll Surg. 2013;217:763769.

13. Till Sr, Morgan DM, Bazzi AA, et al. Reducing surgical site infections after hysterectomy: metronidazole plus cefazolin compared with cephalosporin alone. Am J Obstet Gynecol. 2017;217:187. el-ell.

14. Pihl S, Blomberg M, Uustal E. Internal anal sphincter injury in the immediate postpartum period: prevalence, risk factors and diagnostic methods in the Swedish perineal laceration registry. European J Obst Gynecol Repro Biol. 2020;245:1-6.

15. Fornell EU, Matthiesen L, Sjodahl R, et al. Obstetric anal sphincter injury ten years after: subjective and objective long-term effects. BJOG. 2005;112:312-316.

16. Sultan AH, Monga AK, Kumar D, et al. Primary repair of obstetric anal sphincter rupture using the overlap technique. Br J Obstet Gynaecol. 1999;106:318-323. approximately 112,600 US women who experience OASIS each year.

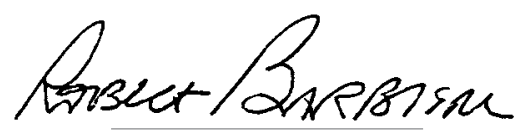

RBARBIERI@MDEDGE.COM

Dr. Barbieri reports no financial relationships relevant to this article.

17. Williams A, Adams EJ, Tincello DG, et al. How to repair an anal sphincter injury after vaginal delivery: results of a randomised controlled trial. BJOG. 2006;113:201-207.

18. Hauth JC, Gilstrap LC, Ward SC, et al. Early repair of an external sphincter ani muscle and rectal mucosal dehiscence. Obstet Gynecol. 1986;67:806-809.

19. Hankins GD, Hauth JC, Gilstrap LC, et al. Early repair of episiotomy dehiscence. Obstet Gynecol. 1990;75:48-51.

20. Ramin SR, Ramus RM, Little BB, et al. Early repair of episiotomy dehiscence associated with infection. Am J Obstet Gynecol. 1992;167:11041107.

21. Pritchard JA, MacDonald PC, Gant NF. Williams Obstetrics, 17th ed. Norwalk Connecticut: Appleton-Century-Crofts; 1985:349-350.

22. Okeahialam NA, Thakar R, Kleprlikova H, et al. Early re-suturing of dehisced obstetric perineal woulds: a 13-year experience. Eur J Obstet Gynecol Repro Biol. 2020;254:69-73.

23. Dudley L, Kettle C, Thomas PW, et al. Perineal resuturing versus expectant management following vaginal delivery complicated by a dehisced wound (PREVIEW): a pilot and feasibility randomised controlled trial. BMJ Open. 2017;7:e012766.

24. Lewicky-Gaupp C, Leader-Cramer A, Johnson $\mathrm{LL}$, et al. Wound complications after obstetrical anal sphincter injuries. Obstet Gynecol. 2015;125:1088-1093. 